\title{
Gradhiva
}

GRADHIV

Revue d'anthropologie et d'histoire des arts

$8 \mid 2008$

Mémoire de l'esclavage au Bénin

\section{Le reflux de la traite négrière : les agudas du Bénin} Carnet photographique

\section{Milton Guran}

\section{(2) OpenEdition}

Journals

Édition électronique

URL : http://journals.openedition.org/gradhiva/1181

DOI : $10.4000 /$ gradhiva. 1181

ISSN : 1760-849X

Éditeur

Musée du quai Branly Jacques Chirac

Édition imprimée

Date de publication : 15 novembre 2008

Pagination : 87-95

ISBN : 978-2-915133-94-3

ISSN : 0764-8928

Référence électronique

Milton Guran, "Le reflux de la traite négrière : les agudas du Bénin », Gradhiva [En ligne], 8 | 2008, mis en ligne le 15 novembre 2011, consulté le 04 mai 2019. URL : http://journals.openedition.org/ gradhiva/1181; DOI : 10.4000/gradhiva.1181 


\section{DOCUMENTS ET MATÉRIAUX | Milton Guran}

\section{Le reflux de la traite négrière : les agudas du Bénin}

A u cours du XIX ${ }^{e}$ siècle, de nombreux Africains affranchis ou fils d'Africains nés au Brésil quittèrent ce pays pour rejoindre les côtes d'Afrique de l'Ouest où ils commençèrent une nouvelle vie. Ce mouvement de retour s'accentua avec la déportation d'anciens esclaves proches de l'Islam qui participèrent à la tentative de soulèvement connue comme la révolte des Malês, qui eût lieu en 1835 à Bahia.

Dans la région, actuellement comprise entre le Nigeria, le Bénin et le Togo, où ils s'installèrent et furent bien accueillis, d'autres Africains libres, pour la plupart des catholiques, les rejoignèrent, encouragés par les perspectives d'avenir. De nombreux commerçants brésiliens, impliqués principalement dans la traite négrière, vivaient déjà dans la région et étaient connus sous le nom d'agudas, mot qui a pour origine le fort portugais de São João de Ajuda à Ouidah. L'expérience acquise au Brésil en tant que tailleurs, menuisiers, maîtres d'œuvres, permit à ces anciens esclaves revenus sur le continent africain, qui parlaient le portugais et étaient pour la plupart alphabétisés, de s'assimiler au milieu des agudas.

La réunion de ces deux groupes, auxquels s'intégrèrent par la suite les descendants de leurs esclaves, dessina le profil de la communauté aguda d'aujourd'hui. En elle, nous retrouvons à la fois l'orgueil des maîtres d'esclaves - statut que la majorité a acquis lors de son arrivée en Afrique - et les habitudes qu'ils avaient adoptées au Brésil en tant qu'esclaves. Parmi ses marqueurs identitaires les plus communs, on trouve des noms famille à consonance lusophone tels que De Souza, Silva, Almeida, etc.

Comme à Bahia, les agudas commémorent la fête de N. S. de Bonfim, dansent la «bourian» - la burrinha, typique manifestation brésilienne de la période de 1800 - et, encore aujourd'hui, chantent en portugais, se réunissent autour de plats comme une feijoada ou d'un kousidou. Au Bénin, même de nos jours, il est courant que les plus anciens se saluent avec un sonore «Bom dia, como passou? ", auquel est répondu, toujours en portugais : «Bem, 'brigado».
Au XIX siècle, beaucoup de ces "Brésiliens » assumèrent par la suite les fonctions d'interprètes auprès de l'administration coloniale et des dignitaires africains, et servirent d'interprètes de la culture occidentale auprès de la population locale. C'est à travers une logique d'alliances matrimoniales et politiques que les agudas devinrent aussi des agents du changement économique, social et politique de la région. L'exemple qui illustre le mieux l'histoire de leur position dominante est celui de Francisco Felix de Souza (1754-1849), devenu "frère de sang " du roi Gezo d'Abomey et son principal allié dans le commerce négrier. Connu également sous le nom de "Chacha », Francisco Felix de Souza favorisa la fixation des agudas dans le royaume dahoméen durant la première moitié du xIX siècle. Ignacio Paraïso (1752-1839) se distingua quant à lui en tant que conseiller du roi de Porto-Novo et, sous l'administration française, comme le premier, et pour longtemps l'unique africain disposant d'un siège au Conseil de la colonie. Plus récemment, en février 1990, $\mathrm{M}^{\mathrm{gr}}$ Isidore de Souza, descendant du Chacha I et Archevêque de Cotonou, se retrouva à la tête de la Conférence des Forces Vives de la Nation, exerçant la fonction de responsable de la transition vers la démocratie suite à la fin du régime du général Mathieu Kérékou.

Dans la constitution de l'identité sociale des communautés aguda, un des aspects les plus importants est le parcours de ces anciens esclaves et leurs descendants qui ont réussi à s'insérer dans une société dont leur groupe avait auparavant été exclu. Ils étaient devenus libres au Brésil mais, dans cette région de l'Afrique, ils continuaient, tout comme leurs descendants, de porter le stigmate de l'esclavage. C'est la mémoire de l'expérience de l'esclavage au Brésil qui a été la matrice de leur identité et qui leur a permis de jouer un rôle important en tant qu'acteurs socio-économiques et citoyens à part entière dans cette région.

Anthropologue et photographe, chercheur au LABHOI, Laboratoire d'Histoire Orale et de l'Image, Université fédérale Fluminense à Rio de Janeiro. mguran@terra.com.br 


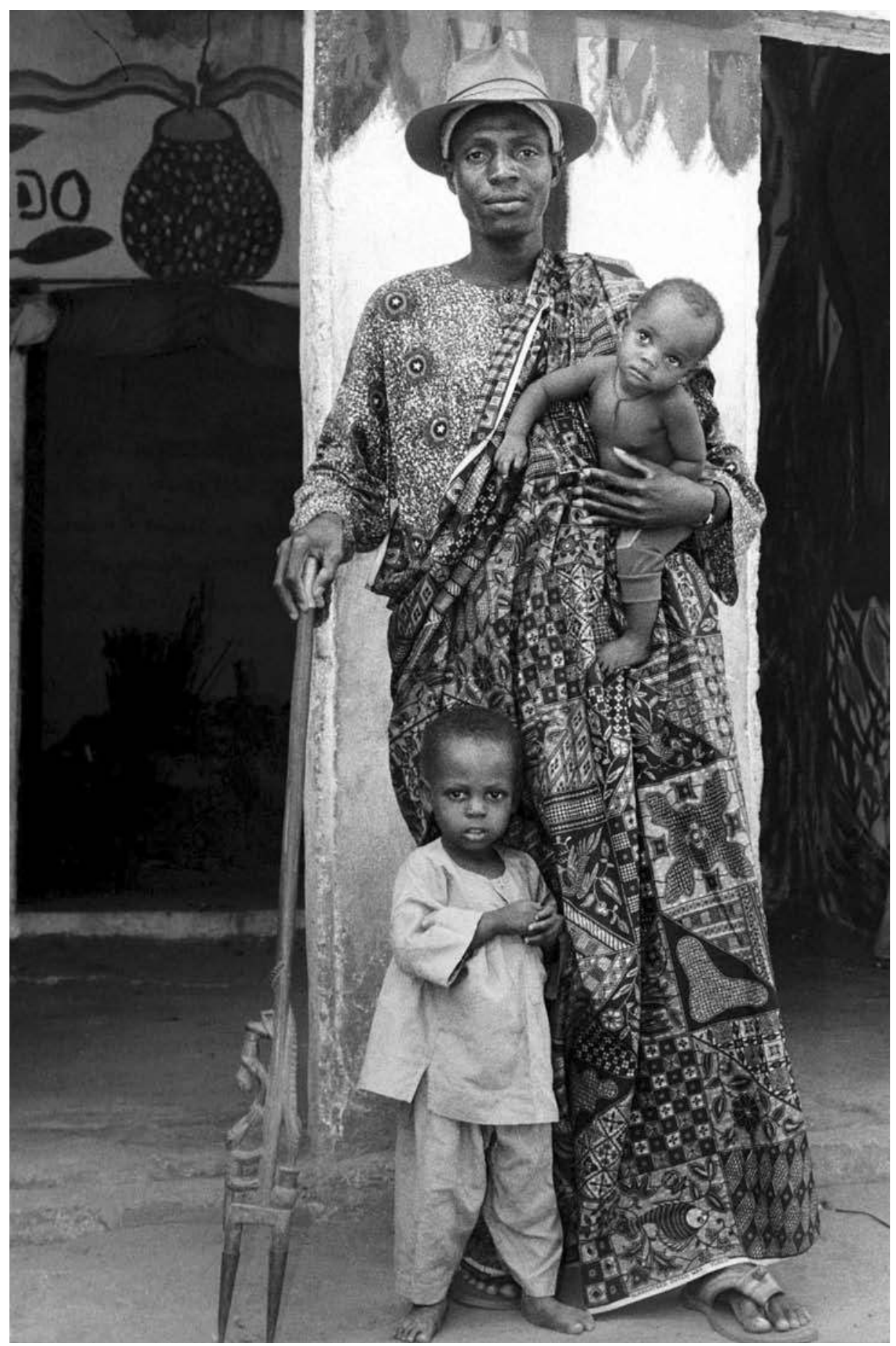

| Parmi les familles "brésiliennes ", la famille de Souza est probablement la seule à posséder son propre vodun, le Dagun, dont l'origine est directement liée au Chacha I. Selon Dah Dagunnon, le chef de culte, le vodun Dagun protège principalement les enfants. 


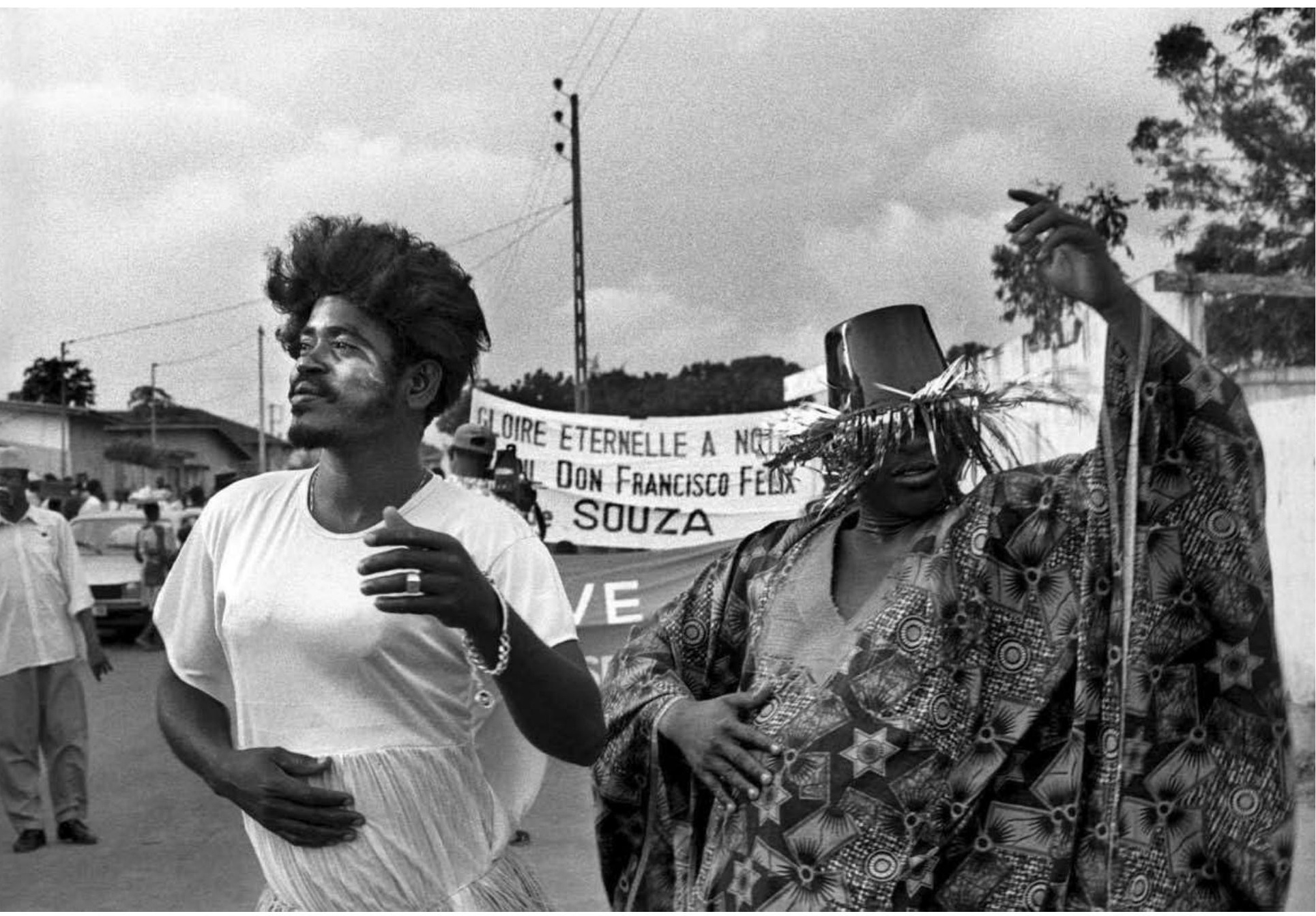

Derrière la banderole sur laquelle se lit « Gloire éternelle à notre ancêtre Dom Francisco Félix de Souza ", des centaines de personnes. Certaines sont déguisées ou utilisent un masque, chantent et dansent au son d'une fanfare. Tout le monde, le jour de l'intronisation du Chacha VIII, récite des louanges en l'honneur de D. Francisco, le Chacha I, dans les rues de Ouidah. 


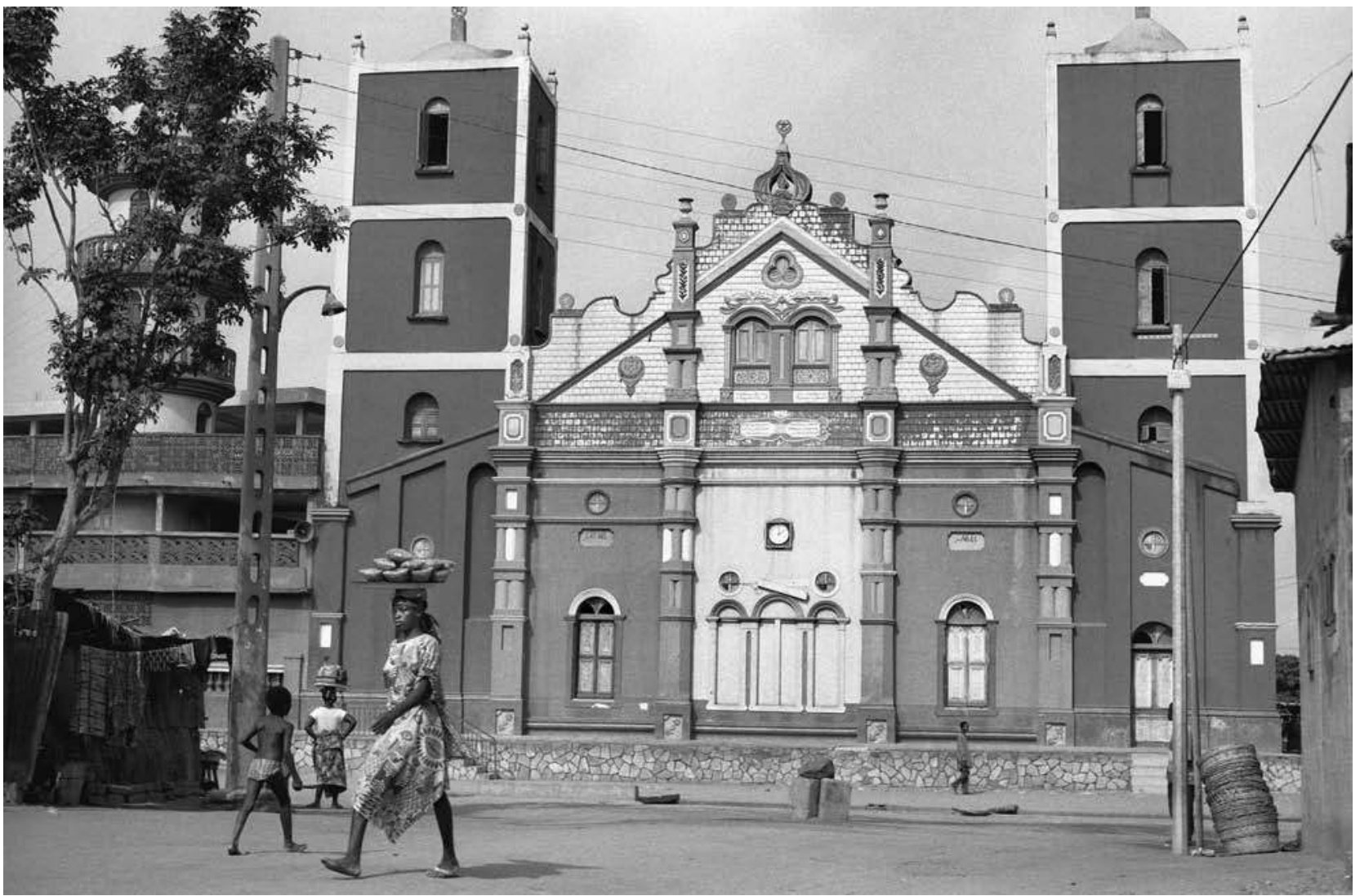

C'est à l'arrivée des agudas que cette région d'Afrique entra dans l'ère des constructions durables en briques, selon une technique spécifique et un style architectural employés au Brésil auxıx siècle. La grande mosquée de Porto-Novo, dont la construction a été achevée en 1930, est un exemple de cette influence brésilienne. La façade de cette mosquée est la copie conforme d'une église baroque de l'État de Bahia (Brésil) à laquelle un minaret a été ajouté. 


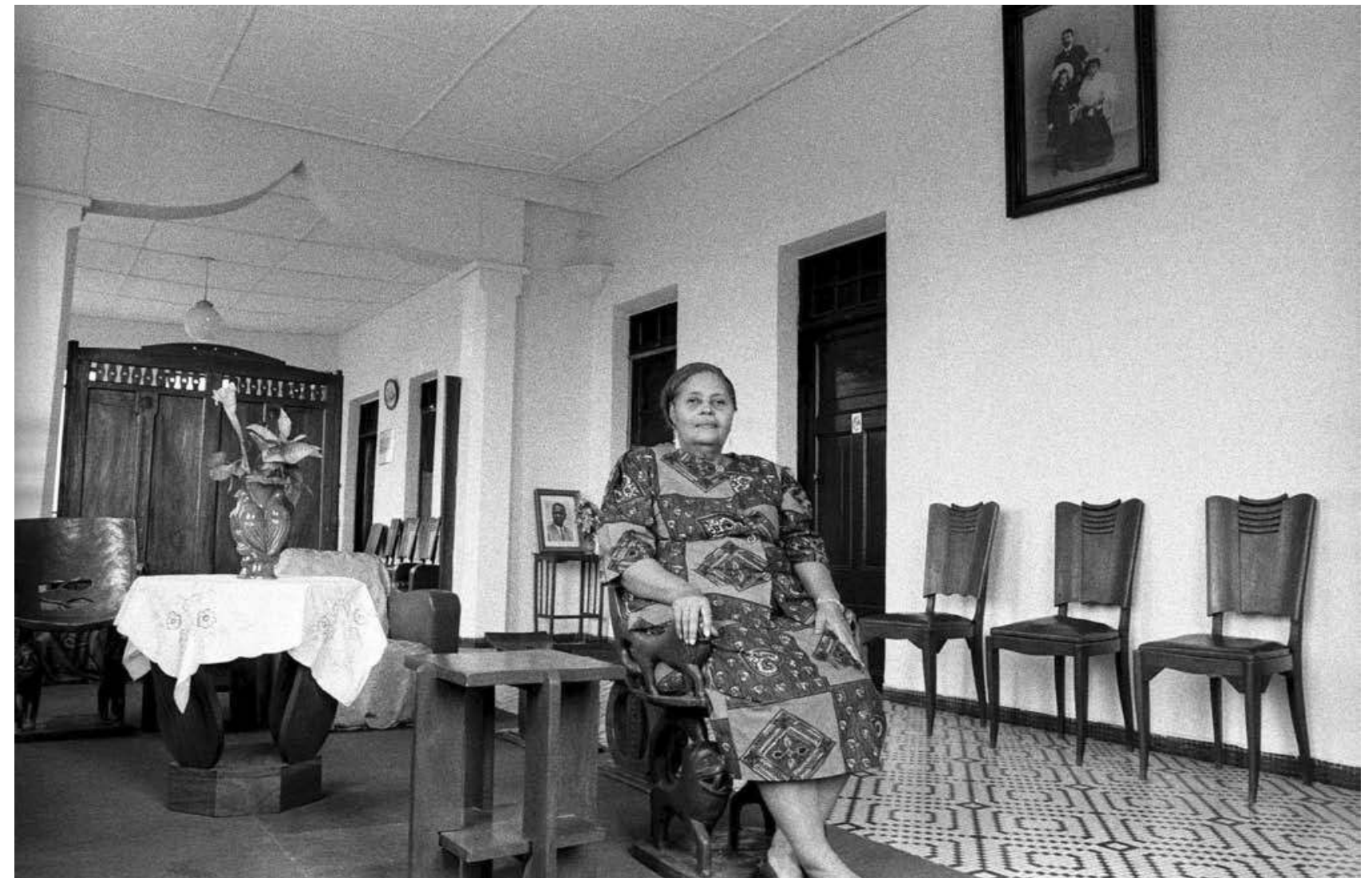

Madame Francisca Patterson, née de Medeiros, arrière petite-fille de Francisco Feliz
de Souza, le Chacha I, dans le salon de sa maison à étages à Porto-Novo, un exemple
de maison «brésilienne ». 


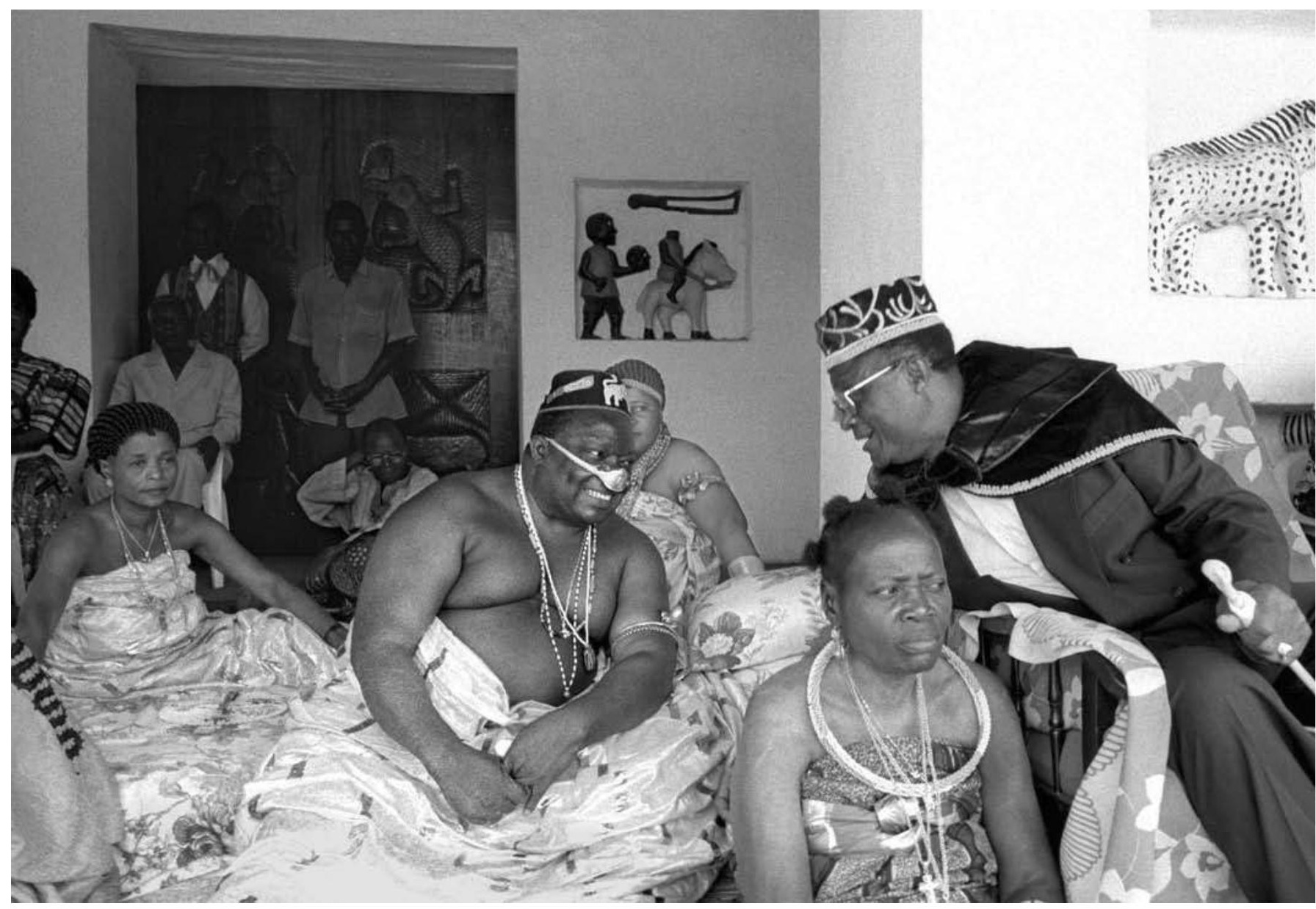

En octobre 1995, lors du $146^{\mathrm{e}}$ anniversaire de la mort de Don Francisco Félix de Souza (le Chacha I), son actuel successeur, le Chacha VIII, a été intronisé à Ouidah, en présence de plus de mille invités et parents de la famille. Parmi eux, deux évêques et huit prêtres catholiques, et des invités tels que l'Ambassadeur du Brésil installé au Nigéria et daagbo Hounon, chef suprême du culte vodun à Ouidah. Après l'intronisation, le Chacha VIII a été reçu par le roi d'Abomey pour la cérémonie de transmission des symboles du pouvoir liés à son titre de représentant du vice-roi de Ouidah. 


\section{DOCUMENTS ET MATÉRIAUX}

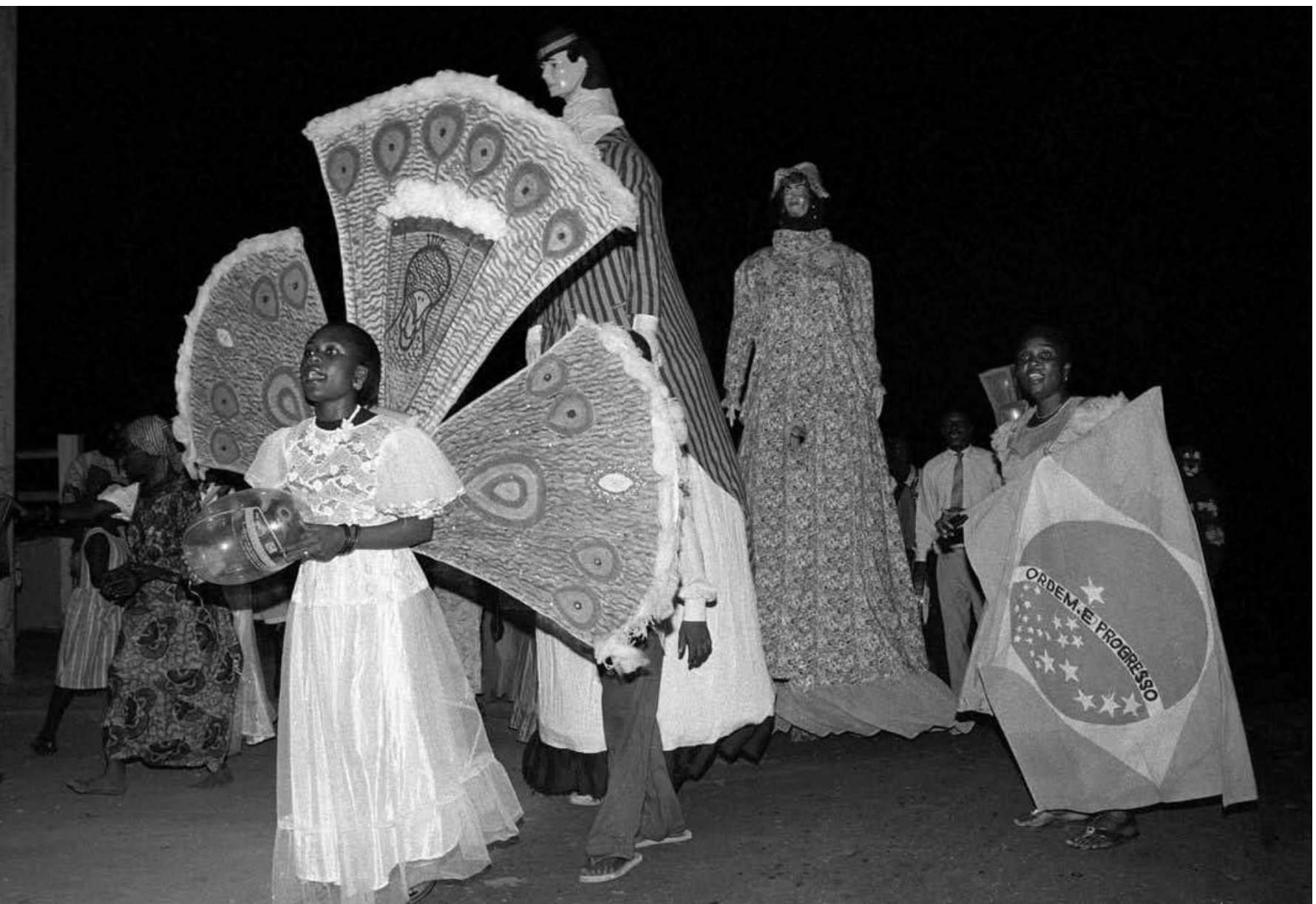

Comme à Bahia, les célébrations de Nossa Senhora do Bonfim ont lieu pendant le mois de janvier au Bénin. La communauté aguda de Porto-Novo tout entière se mobilise et ouvre les festivités par un grand défilé dans les rues de la ville la veille de la messe. L'organisation du défilé et l'ambiance générale rappellent certains moments du carnaval brésilien. La fanfare joue de toutes ses forces et quelques participants, portant des lanternes, forment deux rangées, entre lesquelles d'autres dansent et chantent en portugais : A sociedade brasileira está na rua (la société brésilienne est dans la rue) / venha ver (viens voir) / venha gostar (viens t'amuser) / o brinquedo é delicado (le jouet est fragile) / para quem, para quem (pour celui qui, pour celui qui...) / gosta de ver (aime regarder). 


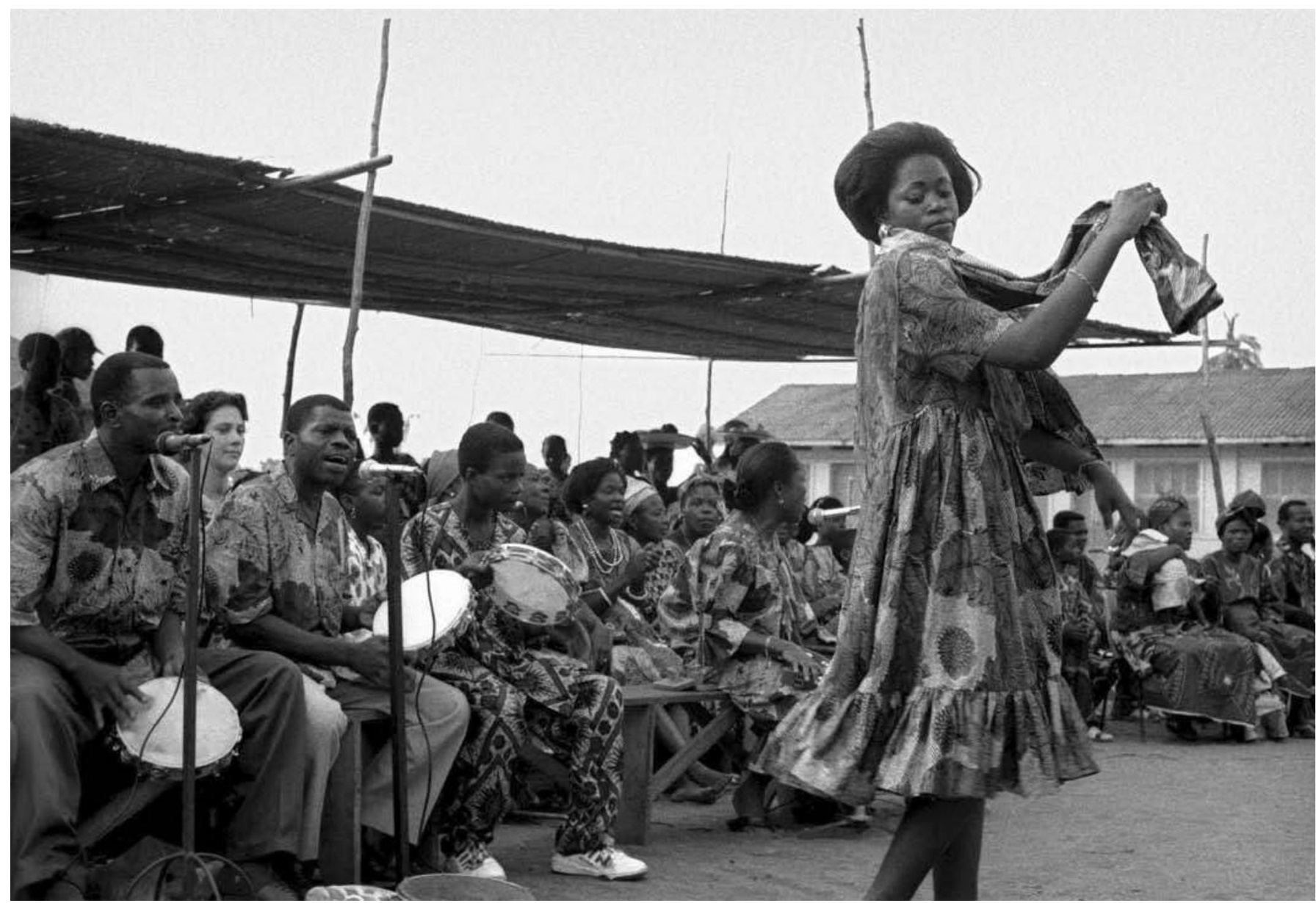

La «samba " à Porto-Novo, dernière célébration en hommage à Nossa Senhora do Bonfim. En arrière-plan, on peut voir l'orchestre de la «bourian ». Au Bénin, la plupart des danses se caractérisent par des mouvements de bras et d'épaules répétitifs, le tronc étant projeté en avant et les jambes plutôt pliées. Dans la "samba ", au contraire, les mouvements des bras et des mains sont plus libres, et s'animent en même temps que les jambes et les pieds. Le corps entier bouge et se prête facilement à des improvisations. 